\title{
Work Activities and Workers' Health in Broiler Production: A Case Study
}

Author(s)
Alencar M do CB de
Naas IA
Gontijo LA
1 Professor of the Department of Health
Sciences of Federal University of São Paulo.
2 Professor of the Department of Agriculture
Engineering of State University of Campinas.
3 Professor of the Department of Production
Engineering of Federal University of Santa
Catarina.

Mail Address

Maria do Carmo B. de Alencar Department of Health Sciences Federal University of São Paulo

E-mail: belinha.alencar1@gmail.com

\section{ABSTRACT}

The objective of this study was to investigate the prevalence of health related symptoms and to analyze the work activities of workers in contracted non-mechanized broiler farms in two regions of the state of Paraná in order to determine possible factors associated to those symptoms. The methods consisted in selecting the houses and the workers, and to apply a questionnaire that included demographic data, questions related to work, the Nordic Questionnaire for Musculoskeletal Symptoms, other symptoms (runny nose, skin itching, throat and eye irritation). In addition, workers were asked if they enjoyed their job, if the supervisor motivated them to work, and if they were afraid to lose their job. Activities were submitted to systematic observations, adapted from Ergonomics, and the loads carried were analyzed and some instruments weighted. The study included 80 workers of both genders between 16 and 59 years, being 40 from each region. There were evidences of low back pain risk in the activities of filling drinkers and washing bell drinkers, with a higher prevalence in region $A$, where automated systems were less frequently used. The study suggests that mechanized filling of feeders, and the use of nipple drinkers may prevent health problems. It was also found that psychosocial aspects were associated to musculoskeletal symptoms. Promoting better working conditions is essential, as these aspects can affect human behavior at work.

\section{INTRODUCTION}

The work in agriculture is a major cause of occupational diseases, with documented musculoskeletal disorders, respiratory diseases, hearing loss, diseases related to the use of pesticides, etc. (Kirkhorn \& Schnenker, 2002; BLS, 2006). Work-related musculoskeletal disorders (WMSDs) include a variety of inflammatory and degenerative conditions that affect muscles, tendons, ligaments, joints, peripheral nerve, including low back pain and myalgia (Punnet \& Wegman, 2004). According to the Brazilian Ministry of Health (Brasil, 2006), WMSDs are characterized by symptoms such as pain, paresthesia, feeling heavy, and fatigue. Some work factors must be investigated, such as muscle exertion and movement repetition, which are associated to the dimensions intensity, velocity, time of exposure, etc. (Marras, 2000; Kumar, 2001).

Several agricultural activities expose rural workers to musculoskeletal disorders (Hildebrandt, 1995; Howard et al., 2005; Chapman et al., 2008; Fathallah et al., 2008). In animal production, there are musculoskeletal disorders associated to activities related to pig production (Stal \& Englund, 2005; Silveira et al., 2008), and respiratory problems are detected in individuals that work in animal production environments, particularly in pig and broiler production (Melbostad et al., 1997; Iversen et al., 2000). 


\section{Alencar M do CB de, Naas IA, Gontijo LA}

\section{A Case Study}

Broilers are intensively produced in Brazil, and this is an important economic activity as the country is the largest world exporter of chicken meat (ABEF, 2007). Due to the relevance of broiler production in Brazil, there are concerns as to occupational health in this industry, and therefore, research in this field is required.

The aim of this study was to investigate the prevalence of health-related symptoms and to analyze the work activities of workers in contracted nonmechanized broiler farms in two regions of the state of Paraná in order to identify possible factors associated to those symptoms.

\section{MATERIAL AND METHODS}

This was an exploratory and descriptive study. It was carried out in a broiler company that had commercial operations in two geographical regions ( $A$ and $B$ ). One of the criteria for selecting the regions was the final productivity in the last three months, thereby characterizing region A as "low productivity" and B as "high productivity" regions.

Workers of integrated non-mechanized broiler farms were chosen because they perform manual activities during the production cycle, and because these farms represent most of the Brazilian broiler production. These workers were under service providing contracts of undetermined time, owned the broiler houses, and received one-day-old chicks as a "flock" and the feed during broiler growth, until harvest for slaughter. The workers were paid at the end of the flock according to a productivity index, which included bird mortality rate and final bird weight. These contracts and services are common in vertically integrated production systems.

After the regions were determined, farms were selected at random. The workers' selection criteria included working inside the broiler houses during rearing and for at least two years. The study complied with ethical considerations: workers were previously informed and voluntarily consented in participating of the study.

The broiler houses were built close to the households in farmer-owned land, and presented the same general characteristics in both regions: they were made of wooden poles, had concrete floors, clay-tiled roofs, inside and outside polyester curtains, and screens on the walls.

The total sample included 80 workers of both genders, with 40 in each region working in 30 farms per region.
The developed questionnaire included demographic data (gender, age, and level of education), and the workers were asked how long they had worked with broilers, number of houses, if they performed the activities alone or not, if that was their only economic activity and others. It also included some questions of the tool Nordic Musculoskeletal Questionnaire (Wilson \& Corlett, 1995) to detect musculoskeletal symptoms, their frequency, and anatomic location; their perception as to the physical effort required in the tasks of broiler production work (a lot, a little, or no physical effort); presence of symptoms after working in the last 30 days (runny nose, skin itching, and throat and eye irritation). In addition, there were personal questions directly related to work, such as if the worker liked rearing pullets to broilers (whether he/she enjoyed that work); whether the supervisor motivated him/her to work; and if he/she feared being suddenly dismissed by the company. The possible answers to these questions were: agree, partially agree, or disagree.

The questionnaire was applied as an interview with the workers with their formal consent, and in a place determined by them. Systematic observations of work activities, adapted from Ergonomics (Guérin et al., 1997), were carried out.

The studied activities were filling the feeders and washing the drinkers after the third week of the flock, recording the equipment used, stances and most frequent movements, and how the work was actually carried out. Workers were observed for three months in two production cycles. Although Ergonomics encompasses multiple dimensions, the present study focused only on the analyses of these activities and hearing of the workers' answers to the questions made or to their complaints during their work activities. Workers' utterances during their activities were recorded.

Also, the weights of the buckets and bags used to fill the feeders were recorded in five measurements per day every other day, using a digital scale (Model R042000, Plenna), in two randomly chosen farms per automation type in both regions ( $A$ and $B$ ). Videos were recorded inside the broiler houses to register the workers activities using a video-camera (model JVC $\left.{ }^{\circledR} \mathrm{GR}-\mathrm{D} 90 \mathrm{UB}\right)$.

Both qualitative and quantitative data were analyzed. Quantitative data were submitted to the tests of Fisher and Odds Ratio, using SAS ${ }^{\circledR}$ statistical package. 


\section{Alencar M do CB de, Naas IA, Gontijo LA}

\section{RESULTS AND DISCUSSION}

Demographic characteristics, number of broilers houses in the farm, years of work, and economic activity are shown in Table 1. Low level of formal education and the was observed in both regions.

\begin{tabular}{lcc}
\hline \multirow{2}{*}{$\begin{array}{l}\text { Table } 1 \text { - Demographics, years of work, number of houses, andif } \\
\text { that was the single worker's economic activity per region. }\end{array}$} \\
\cline { 2 - 3 } Parameters & \multicolumn{2}{c}{ Region } \\
\hline Age (years) & 17 a 58 & 16 a 59 \\
Female & $42.5 \%$ & $32.5 \%$ \\
Male & $57.5 \%$ & $67.5 \%$ \\
Schooling, elementary school & $72.5 \%$ & $75.0 \%$ \\
Only 1 broiler house per farm & $50.0 \%$ & $40.0 \%$ \\
More than 1 broiler house per farm & $50.0 \%$ & $60.0 \%$ \\
Years of work, more than five years & $87.5 \%$ & $85.0 \%$ \\
Single economic activity (broiler production) & $55.0 \%$ & $32.0 \%$ \\
\hline
\end{tabular}

The workers were more economically dependent on broiler production in region $\mathrm{A}$ than in $\mathrm{B}$. At the time of the study, the company was undergoing financial problems, and was delaying the payment of the farmers in both regions, leading to extra stress to the workers. It must be mentioned that farm owners and relatives of the owners worked in the broiler houses.

Musculoskeletal pain in the last 12 months at least once a month was reported by $61.0 \%$ of the workers in region $A$, and $50.0 \%$ in region $B$. Some workers reported having felt pain more than once. Figure 1 shows the anatomic location of the musculoskeletal pain felt in the last 12 months at least once a month per region. The frequency of the pain in the last 30 days was in $20.0 \%$ of the workers from region $A$ that reported pain, and $5.0 \%$ in region $B$. The most frequent location of pain found was the low back, agreeing with the study of Barrero et al. (2006) which determined a high prevalence of low back pain in farmers due to the physical strain caused by manual work activities. Fathalah et al. (2008) mention that the number of epidemiological studies on low back pain in agriculture is low as compared to other industries.

The workers reported other symptoms felt in the last 30 days, as shown in Figure 2. More than one symptom was reported by $47.5 \%$ of the workers, and $60.0 \%$ of these were from region $A$. Runny nose and throat and eye irritation may be associated to the exposure of allergens inside the broiler house due to dust in suspension in the air. According to Hirata \& Mancini Filho (2002), several fungi may be present in the dust, playing an important role as allergens in humans. In addition, throat and respiratory pathways
Work Activities and Workers' Health in Broiler Production: A Case Study

can also be irritated by the ammonia gas generated inside the poultry houses. Nääs et al. (2007) reported, in a study on two ventilation types in broiler houses, ammonia concentration levels. As to work activities, out of the 80 interviewed workers, $75.0 \%$ filled manually the feeders in region $B$, and $97.5 \%$ in region A. In some farms, feeders were automatically filled. Feeders were filled using carts and buckets or no carts (using only buckets or bags). When the cart was used, the worker filled the buckets from the silo. The buckets weighed $23.0 \mathrm{~kg}$ each, in average, and were manually hoisted to the cart by the worker.

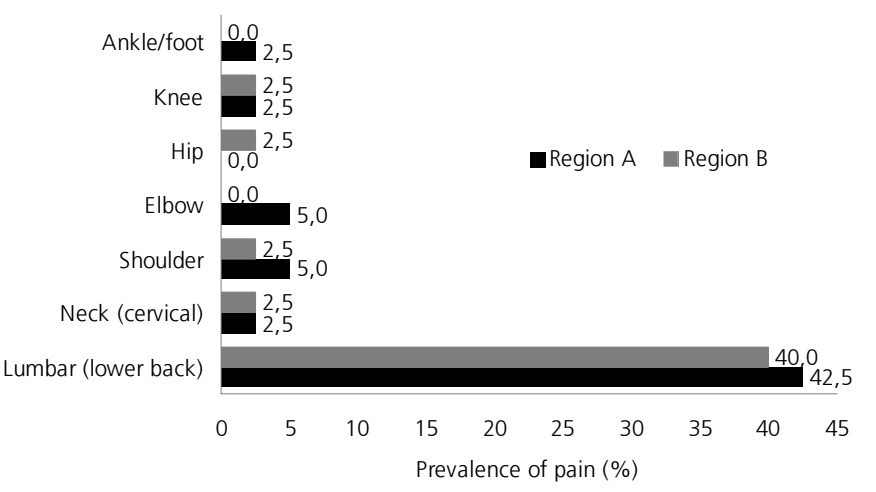

Figure 1 - Musculoskeletal pain (location) in the last 12 months occurring at least once a month, per region.

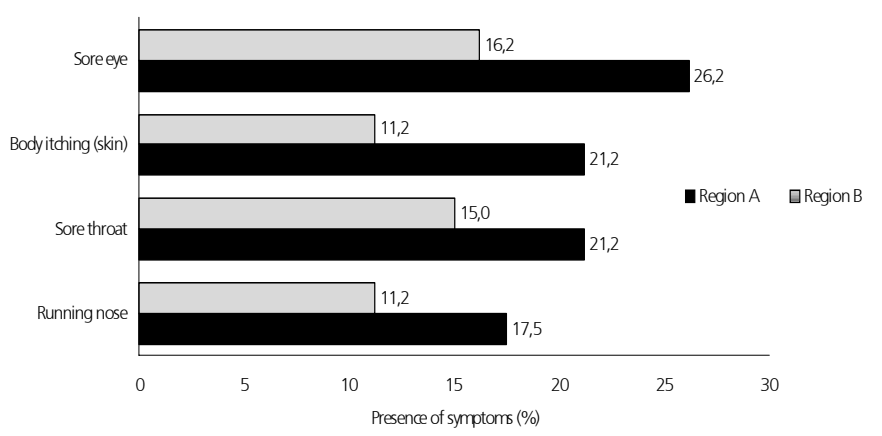

Figura 2 - Presence of health symptoms in the last 30 days, as reported by the workers, per region.

Each cart carried about 10 buckets, and was filled approximately three to five times. The worker then lifted the bucket to fill the feeders, at a rate of six feeders per bucket. There were around 360 feeders per house. When carts were not used, the worker manually filled the feeders using bags or buckets.

Figure 3 shows a worker manually carrying a feed bag. Bags weighed $20.0 \mathrm{~kg}$, in average. Both described types of filling pose back pain risks due to transporting loads and to trunk flexion movements (leaning forward) to pour the feed. When no carts are used, the transport 


\section{Alencar M do CB de, Naas IA, Gontijo LA}

Work Activities and Workers' Health in Broiler Production: A Case Study

of feed in bags or buckets was in general, and the distance carrying the bags or buckets is longer. Forward trunk regions flexion may cause low back pain, particularly when the flexion angle increases (Fathallah et al., 1998; Cheng, 2000). Trunk bending repetitive movements and unilateral load carrying may also result in low back pain (Granata \& Marras.1995; Marras, 2000). According to NR-17 (2001) Ergonomics Regulations, appropriate Technical norms must be used to limit or to ease manual load transport. The workers that filled feeders using carts had lower chance of having musculoskeletal pain (OR=1.25, $\alpha=0.05)$. In addition, most had worked for more than five years in direct contact with the birds.

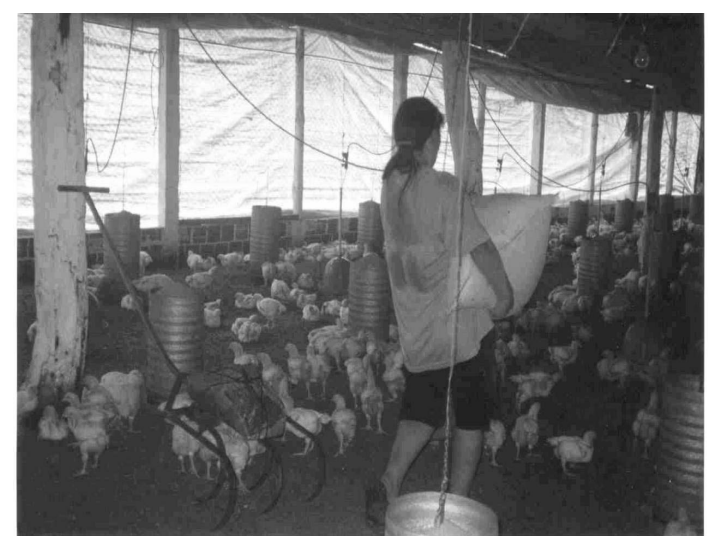

Figure 3 - Manual filling of the feeders with bags (region A).

The activities of filling feeders and washing drinkers were performed by $27.5 \%$ workers alone in region $A$ and $15.0 \%$ in region $B$. In general, two workers carried out these activities.

In region $B$, the number of male workers was higher as compared to region $A$, where a higher number of daily musculoskeletal pain complaints was recorded. Maciel et al. (2006) mentions that the differences in muscle mass, body composition, and size of women relative to men may represent a predisposing risk factor for work related pain symptoms in women.

Drinkers were also manually washed with the aid of buckets and bags. In region A, $92.5 \%$ of the workers flexed the trunk to wash the bell drinkers as compared to $30.0 \%$ in region $B$, where some farms were equipped with nipple drinkers, making drinker cleaning easier and reducing the time of permanence inside the broiler house. The stances observed during the washing of the bell drinkers present a risk to the coming out of low back pain.

The perception of the physical effort required to perform work activities in broiler production was that a lot of effort is required (38.7\% of the workers) or little effort $(46.2 \%)$. The etiology of musculoskeletal disorders is multifactorial. Therefore, organizational aspects, such as work division, tasks processes, rhythm of work, and psychosocial aspects, related to the set of perceptions and experiences of the workers, also influence the emergence of musculoskeletal pain.

Dust is produced in broiler houses during rearing, causing runny nose and sneezes in some workers. This is expressed in the utterance of a worker as to work conditions: "It gives me a sneezing symptom fit. It is the dust," while other said: "the smell and the dust inside the house irritates my eyes and my throat, " and still other: "sometimes, my nose even bleeds." Alencar et al. (2004) found that workers that perform tasks inside broiler houses, in more than two houses per day, and for more than five years, are exposed to respiratory health risks. As the complaints of these symptoms were more frequent in region $A$ than $B$, it is suggested that their cause is the longer permanence of the workers inside the houses, as the manual activities of both filling feeders and washing drinkers takes longer time in region $A$; however, this warrants further investigation. Also, in some houses of region A, feeders and drinkers were not properly aligned, making it difficult for the workers to know which feeders had already been filled or drinkers had already been washed. There were statistical associations between work related aspects and the presence of musculoskeletal pain, as analyzed among the workers of both regions (Table 2). The psychosocial factors that influenced the presence of musculoskeletal pain were: does not enjoy rearing broilers, the supervisor does not motivate him/her to work, and fears being suddenly dismissed by the

\begin{tabular}{lcc}
\hline Table 2 - Associations between work-related aspects and musculoskeletal pain. & Table of probabilities \\
\hline $\begin{array}{l}\text { Associations between work-related aspects } \\
\text { and musculoskeletal pain }\end{array}$ & $\begin{array}{c}\text { P- value } \\
\text { Enjoys or not rearing broilers }\end{array}$ & $\begin{array}{c}\text { Odds Ratio } \\
\text { (OR) }\end{array}$ \\
Supervisor motivates or not & 0.0118 & 0.0396 \\
Being afraid to be suddenly dismissed by the company & 0.0018 & 0.0237 \\
\hline
\end{tabular}

$(\alpha=0.05)$. 


\section{Alencar M do CB de, Naas IA, Gontijo LA}

Work Activities and Workers' Health in Broiler Production: A Case Study

company. Some authors mention the influence of psychosocial factors on musculoskeletal pain conditions (Howard et al., 2005; Theorell et al., 1991). Bigos et al. (1991) described the combination of low satisfaction in work with low back pain. According to Bongers et al. (1993), time pressure, in the sense of hurriedly performing a work activity due to some kind of pressure, accelerates movements, and stress increases the intensity of muscle contraction, leading to higher pain sensitivity. Lipp (1996) also stated that stressful situations cause muscle tension and changes in the immune system.

When the use of mechanization is not possible, training is necessary, as well as the utilization of personal protection equipment (PPE). Improving the aspects of the work conditions discussed in the present study is essential both for the protection of workers' health and for the improvement of their productivity due to the influence these aspects have on human behavior during their work activities.

\section{CONCLUSIONS}

Workers from region A presented more musculoskeletal pain and other symptoms than those from region $B$. This may be explained by the fact that the activities of filling the feeders and washing the drinkers had to be manually performed more frequently in region $A$ than $B$, demanding longer permanence of the workers in the broiler houses, among other possible factors. In both regions, some psychosocial aspects were also associated to musculoskeletal pain in the workers. The results showed that some manual activities inside the broilers house lead to a risk to workers' health, including low back pain due to described activities, and respiratory symptoms due to the long permanence inside the broiler house to carry out those tasks. Results suggest that the automation of the broiler houses, with automatic filling of the feeders and the use of nipple drinkers, can reduce the risks of musculoskeletal pain, as well the time of permanence of the workers inside the broiler house. The aspects and their inter-relationships discussed here need further investigation.

\section{REFERENCES}

Associação Brasileira dos Produtores e Exportadores de Frangos. Relatório Anual de 2007 [citado 2008 mar 13]. Disponível em: www.abef.com.br.
Alencar M do CB de, Gontijo LA, Nääs IA. Respiratory risks in broiler production workers. Revista Brasileira de Ciência Avícola 2004; 6(1):23-29.

Barrero LH, Hsu YH, Terwedow H, Perry MJ, Dennerlein JT, Brain JD, $\mathrm{Xu} \mathrm{X}$. Prevalence and physical determinants of low back pain in a rural Chinese population. Spine 2006; 32(23):2728-2734.

Bigos SJ, Battié MC, Spengler DM, Fisher LD, Fordyce WE, Hansson $T$, Nachemson AF, Wortley MD. A prospective study of work perceptions and psychosocial factors affecting the report of back injury. Spine 1991; 16(1):1-6.

Bongers PM, Winter CR, Kompier MAJ, Ildebrandt VH. Psychosocial factors at work and musculoskeletal disease. Scandinavian Journal of Work Environment Health 1993; 19:297-312.

Bureau of Labor Statistics. Occupational outlook handbook, 200607. Washington: US Department of Labor; 2006.

Brasil. Ministério da Saúde. Lesões por esforços repetitivos (LER)/ Distúrbios Osteomusculares relacionados ao trabalho (DORT): dor relacionada ao trabalho. Protocolos de atenção integral à Saúde do Trabalhador de Complexidade Diferenciada. Brasília; 2006.

Chapman LJ, Newenhouse AC, Meyer RH, Tavieira AD, Karsh B-T, Ehlers JJ, Palermo T. Evaluation of an intervention to reduce musculoskeletal hazards among fresh market vegetable growers. Applied Ergonomics 2004; 35:57-66.

Cheng YL. Predicting the vertebral inclination of the lumbar spine. Ergonomics 2000; 43:744-751.

Fathalah FA, Marras WS, Parnianpour M. The role complex, simultaneous trunk motions in the risk of occupational-related low back disorders. Spine 1998; 23(9):1035-1042.

Fathallah FA, Miller BJ, Miles JA. Low back disorders in agriculture and the role of stooped work: scope, potential, interventions, and research needs. Journal of Agricultural Safety and Health 2008; 14(2):221-245.

Granata K, Marras W. EMG-assisted model of biomechanical loading during free-dynamic lifting. Journal of Biomechanics 1995; 28: 1309-1317.

Guérin F, Laville A, Daniellou F, Duraffourg J, Kerguelen A. Compreender o trabalho para transformá-lo: a prática da ergonomia. São Paulo: Ed. Edgard Blucher; 1997.

Hildebrandt VH. Musculoskeletal symptoms and workload in 12 branches of Dutch agriculture. Ergonomics 1995; 38(12):25762587.

Hirata MH, Mancini Filho J. Manual de biossegurança. São Paulo: Ed. Manole; 2002.

Howard NL, Spieholz P, Cohen MA, Silverstein B. Self-reported musculoskeletal symptoms and observed risk factors in bareroot tree nurseries. Journal of Agricultural Safety and Health 2005; 11(1): 19-33. 


\section{Alencar M do CB de, Naas IA, Gontijo LA}

Iversen M, Kirychuk S, Drost $\mathrm{H}$, Jacobson L. Human effects of dust exposure in animal confinement buildings. Journal of Agricultural Safety and Health 2000; 6(4):238-283.

Kirkhorn SR, Schenker MB. Current health effects of agricultural work: respiratory disease, cancer, reproductive effects, musculoskeletal injuries, and pesticide-related illness. Journal of Agricultural Safety Health 2002; 8(2):199-214, 2002.

Kumar S. Theories of musculoskeletal injury causation. Ergonomics $2001 ; 44: 17-47$.

Lipp MEN. Pesquisas sobre stress no Brasil: saúde, ocupações e grupos de risco. São Paulo: Ed. Papirus; 1996.

Maciel ACC, Fernandes MB, Medeiros LS. Prevalência e fatores associados à sintomatologia dolorosa entre profissionais da indústria têxtil. Revista Brasileira de Epidemiologia 2006; 9(1):94102.

Marras WS. Occupational low back disorder causation and control. Ergonomics 2000; 43(1):880-902.

Melbostad E, Eduard W, Magnus P. Chronic bronchitis in farmers. Scandinavian Journal of Work Environment Health 1997; 23(4):271280.

Nääs IA, Miragliotta MY, Baracho MS, Moura DJ. Ambiência aérea em alojamento de frangos de corte: poeira e gases. Engenharia Agrícola 2007; 27(2):326-335.

Norma Regulamentadora NR-17. Manual de legislação, segurança e medicina do trabalho. São Paulo: Ed. Atlas; 2001.

Punnet L, Wegman DH. Work-related musculoskeletal disorder: the epidemiologic evidence and the debate. Journal of Electromyography and Kinesiology 2004; 14:85-93.

Silveira LA, Nääs IA, Moura DJ, Salgado DD, Silva RTR. Labor activities and occupational health in Brazilian swine production - a case study. CIGR E- Journal 2008; 10:1-8

Stal M, Englund JE. Gender difference in prevalence of upper extremity musculoskeletal symptoms among Swedish pig farmers. Journal of Agricultural Safety and Health 2005; 11(1):7-17.

Theorell T, Ringdahl-Harms K, Ahlberg-Hulten G, Westin B. Psychosocial job factors and symptoms from locomotor system- a multicausal analyses. Scandinavian Journal of Rehabilitation Medicine 1991; 23:165-173.

Wilson JR, Corlett EN. Evaluation of human work: a practical ergonomics methodology. New York: Taylor \& Francis; 1995. 